\title{
Entendendo as limitações do uso das figuras de Lissajous para medir a velocidade do som
}

\author{
Understanding the limitations of using Lissagous figures to measure the speed of sound
}

\author{
Theo Z. Pavan*
}

Departamento de Física, Faculdade de Filosofia, Ciência e Letras de Ribeirão Preto, Universidade de São Paulo, Ribeirão Preto, SP, Brasil

Recebido em 22 de Agosto, 2016. Revisado em 13 de Setembro, 2016. Aceito em 14 de Setembro, 2016.

\begin{abstract}
Em artigo recente publicado nessa revista apresenta-se um método para determinar a situação de ressonância em uma coluna de ar, para o cálculo da velocidade do som, usando a técnica de obtenção de fase por curvas de Lissajous. Contudo, alguns aspectos teóricos necessários para o melhor entendimento da técnica, bem como algumas limitações de seu uso podem ser mais bem explorados. Essa nota foi escrita com o objetivo de aperfeiçoar esses aspectos, o que deve ser útil para futuros leitores do artigo. Palavras-chave: Acústica, velocidade do som, figuras de Lissajous, tubo de Kundt, vibrômetro Laser Doppler.
\end{abstract}

In a recent article in this journal there is a description of a method to determine the resonance of an air column, to calculate the speed of sound, using Lissajous curves. However, some theoretical aspects to improve the understanding of this technique, as well as some limitations of its use can be better exploited. This note was written with the aim of improving those aspects which should be useful for future readers of the paper.

Keywords: Acoustics, speed of sound, Lissajous curves, Kundt's tube, Laser Doppler vibrometer.

Durante a disciplina Física Experimental - Ondas, Fluídos e Termodinâmica para alunos do curso de Física Médica da USP de Ribeirão Preto um grupo de alunos apresentou o interessante artigo [1], o qual gerou uma frutífera discussão. Resumidamente, o artigo apresenta um método para determinar a situação de ressonância em uma coluna de ar, para o cálculo da velocidade do som no ar, usando a técnica de obtenção de fase por curvas de Lissajous. Nesse método, o ponto de ressonância foi assumido quando a fase entre a tensão aplicada sobre um alto falante, trabalhando como pistão, posicionado próximo à extremidade aberta de um tubo e o sinal adquirido por um microfone posicionado próximo ao falante fosse exatamente 90 graus. Durante a discussão, houve grande dificuldade por parte dos alunos na compreensão do motivo de a ressonância acontecer justamente na situação de 90 graus de defasagem,

*Endereço de correspondência: theozp@usp.br o que é o ponto fundamental do método. Posteriormente, lendo o artigo com mais calma, verifiquei que essa explicação não está claramente colocada. Por esse motivo resolvi escrever essa nota à Revista Brasileira de Ensino de Física, com o objetivo de aperfeiçoar a compreensão do fenômeno por futuros leitores.

Consideremos que uma onda sonora plana e harmônica se propaga dentro do tubo de ar. Os deslocamentos de ar que surgem devido à passagem dessa onda na direção $+x$ podem ser descritos como:

$$
u(x, t)=U \cos (k x-\omega t+\phi),
$$

sendo $k$ o número de onda, $\omega$ a frequência angular da onda e $\phi$ a fase. Esses deslocamentos induzem mudanças locais na densidade do ar que podem ser associadas a mudanças de pressão. É possível mostrar que a onda de pressão sonora correspondente a essa onda de deslocamento pode ser obtida por [2]: 


$$
p(x, t)=-\rho_{0} c^{2} \frac{\partial u}{\partial x}
$$

sendo $\rho_{0}$ a densidade e $c$ a velocidade do som no meio. Portanto, as variações de pressão devido à propagação dessa onda são descritas como:

$$
p(x, t)=P \operatorname{sen}(k x-\omega t+\phi),
$$

com $P=\rho_{0} c^{2} k U$. Isso indica que as ondas de pressão e deslocamento estão defasadas de 90 graus entre si.

Consideremos essa onda sonora viajando em um tubo finito, como o estudado em [1]. Ao encontrar a extremidade fechada rígida do tubo, essa onda será refletida e o eco viajará da direção - $x$. Esse eco, ao viajar todo o tubo e encontrar a extremidade aberta, também será refletido no caso em que o raio de abertura do tubo seja menor que o comprimento de onda [3]. Quando as ondas viajando em sentidos opostos se interferem de maneira construtiva em uma determinada região do espaço, a situação de ressonância é atingida. Isso acontece quando os ecos sucessivos reforçam a pressão na face do pistão (no nosso caso a face do alto-falante) [3]. Para isso ocorrer, a velocidade da face do pistão deve ser máxima no instante em que a velocidade de deslocamento das partículas de ar, em contato com o pistão, devido à passagem da onda também for máxima. Esse fato pode ser bem visualizado ao fazermos a analogia com um balanço, que entra em ressonância quando a velocidade do braço de quem está empurrando é máxima no instante em que o balanço também atinge sua máxima velocidade.

Assumindo que o sinal de voltagem aplicado ao alto falante está em fase com o deslocamento da sua película, o máximo deslocamento da película do alto-falante é atingido quando a voltagem máxima é aplicada. Consequentemente, a velocidade de deslocamento da película está defasada de 90 graus da voltagem aplicada. Como o microfone responde a variações de pressão, se assumirmos que a voltagem lida na sua saída está em fase com a velocidade de deslocamento das partículas o sinal de voltagem aplicado ao alto-falante estaria defasado de 90 graus do sinal do microfone, na situação de ressonância, como hipótese dos autores de [1].

Para explorar ainda mais esse método, fizemos um experimento similar ao proposto em [1]. Basicamente, usamos um tubo cilíndrico de acrílico com 4,5 $\mathrm{cm}$ de diâmetro e $128 \mathrm{~cm}$ de extensão. Em uma das extremidades do tubo foi colocado um alto-falante e um microfone. Em nosso experimento utilizamos ambas as extremidades abertas, pois no lado oposto ao alto-falante foi posicionado um vibrômetro Laser Doppler (Ometron VQ-500-D-V, Brüel and Kjær Sound \& Vibration A/S, Nærum, Dinamarca) para adquirir a informação de velocidade de deslocamento da película do alto-falante. A montagem experimental está mostrada na Fig. 1. Para cada frequência sonora emitida pelo alto-falante, na qual o sistema entrou em ressonância, foram adquiridas a voltagem aplicada ao alto-falante, a voltagem de saída do microfone e o sinal de saída do vibrômetro Laser Doppler. Para confirmar que o sistema atingia o ponto de ressonância foi distribuído pó de isopor ao longo do tubo de acrílico, o que nos proporcionou um tubo de Kundt. Considerávamos que o sistema estava em ressonância no exato momento em que as partículas de isopor estavam com máxima amplitude de oscilação.

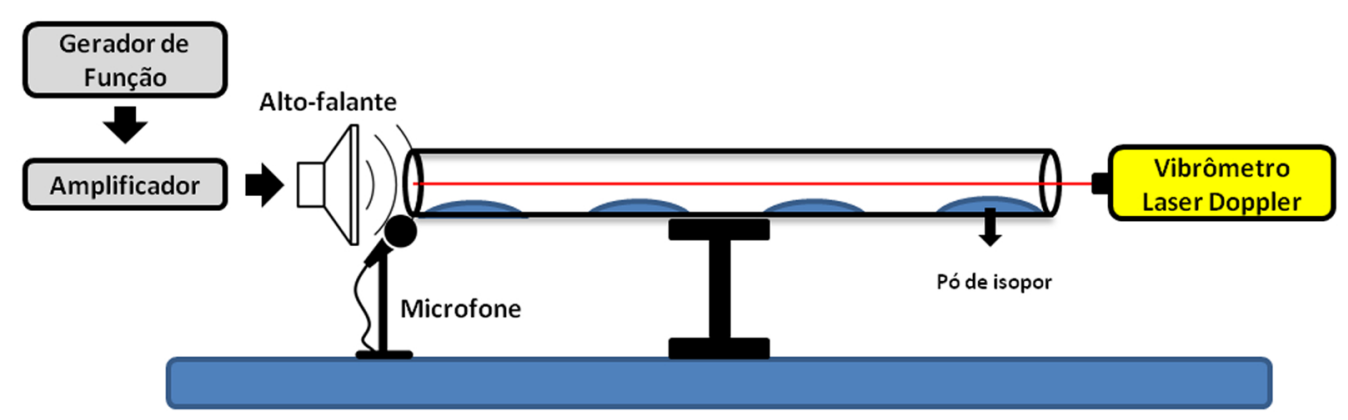

Figura 1: Montagem experimental. Foi usado um tubo de ressonância com ambas as extremidades abertas. Em uma das extremidades do tubo foi posicionado um alto-falante e na outra um vibrômetro Laser Doppler responsável por detectar o movimento da película do alto-falante. Colocamos pó de isopor no tubo para confirmar que o sistema entrava em ressonância. 
Vibrômetro x Alto-falante

$904 \mathrm{~Hz}$

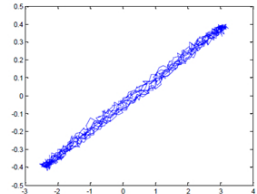

$777 \mathrm{~Hz}$

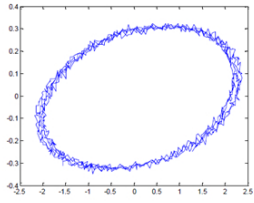

$644 \mathrm{~Hz}$

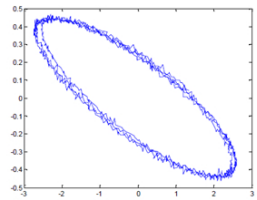

$515 \mathrm{~Hz}$

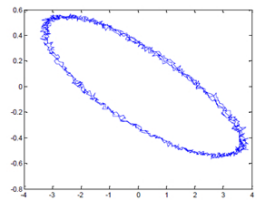

$387 \mathrm{~Hz}$

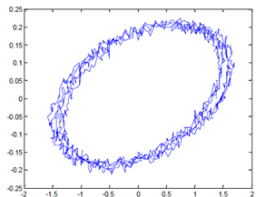

$257 \mathrm{~Hz}$

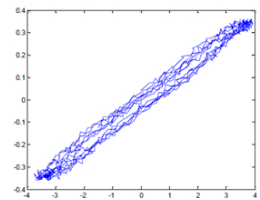

Alto-falante x Microfone

$904 \mathrm{~Hz}$

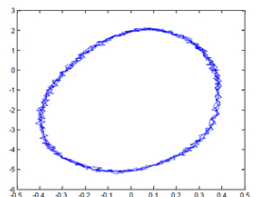

$777 \mathrm{~Hz}$

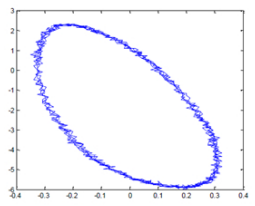

$644 \mathrm{~Hz}$

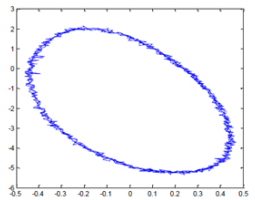

$515 \mathrm{~Hz}$

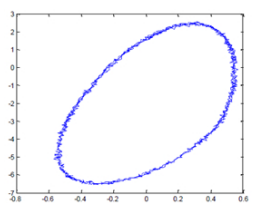

$387 \mathrm{~Hz}$

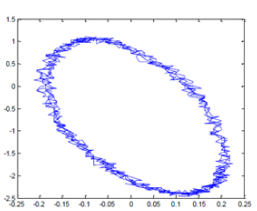

$257 \mathrm{~Hz}$

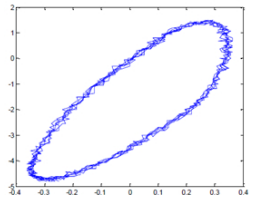

Figura 2: Curvas de Lissajous obtidas para diferentes frequências de ressonância. Na coluna da esquerda estão as figuras obtidas entre o sinal do vibrômetro e o aplicado ao alto-falante, enquanto que na coluna da direita estão as figuras entre o sinal de voltagem aplicado ao alto-falante e o lido pelo microfone. Os eixos das abscissas e ordenadas estão todos em Volts.

A Fig. 2 mostra as curvas de Lissajous obtidas entre o sinal de voltagem aplicado ao alto-falante e o lido pelo microfone, e também entre o sinal do vibrômetro e o aplicado ao alto-falante.

Os gráficos mostrados na coluna da direita da Fig. 2 indicam que a fase entre o sinal do microfone e do alto-falante não foi de $90^{\circ}$ para todas as frequências em que o sistema entrou em ressonância, o que vai de encontro com a hipótese apontada pelos autores em [1]. Para entender esses resultados, podemos analisar os gráficos mostrados na coluna da esquerda da Fig. 2. Esses gráficos indicam que a fase entre o movimento da película e a voltagem aplicada ao alto-falante variou para as diferentes frequências usadas. Portanto, invalidando a ideia, que foi apontada nos parágrafos anteriores, de que a voltagem aplicada ao alto falante estaria sempre $90^{\circ}$ defasada com relação à velocidade de movimento de sua película. Dessa forma, podemos concluir que a fase entre voltagem aplicada ao alto-falante e o movimento de sua película está intimamente relacionada à fase entre as voltagens do microfone e alto-falante. Vimos ainda que a relação de fase do sinal aplicado ao falante e o deslocamento induzido à película não é trivial. Existe vasta literatura que trata do tema; o leitor pode, por exemplo, consultar [4]. Outra complicação é a fase entre a movimentação da película do microfone e sua voltagem de saída, a qual também não é uma função trivial. Portanto, verifica-se que determinar a fase entre voltagens aplicada ao falante e lida pelo microfone na frequência de ressonância pode não ser tão direta como uma análise inicial sugere.

Entendo que o método proposto no artigo [1] é interessante, pois permite obter com boa precisão a velocidade do som no ar sem a necessidade de depender da acuidade auditiva do experimentador para determinar as frequências de ressonância, além de envolver diferentes conceitos de diferentes áreas da física básica. Contudo, a análise desenvolvida nessa nota mostra que a técnica não pode ser generalizada para qualquer frequência que o sistema atinge a ressonância.

\section{Referências}

[1] F. Baraúna, J. Furtado e S. Perez, Rev. Bras. Ensino Física 37, 3310 (2015).

[2] H.M. Nussenzveig, Curso de Física Básica 2: Fluídos, Oscilações e Ondas, Calor (Editora Edgard Blucher, São Paulo, 2001).

[3] A.D. Pierce, Acoustics: An Introduction to Its Physical Principles and Applications (Editora Acoustical Society of America, Woodbury, 1989).

[4] W. Klippel and J. Schlechter, in: Anais do 121 Audio Engineering Society Convention (AES, New York, 2006), p. 6882. 